\title{
CULTURE D'UN PROTISTE PATHOGẼNE ISOLÉ DU SYSTÈME GÉNITAL ET DE DIVERS ORganes DE PRIMATES
}

\author{
G. CHAUVIER*, J. MORTIER-GABET*
}

RÉSUMÉ. Ún milieu diphasique relativement simple, dont la composition est donnée, permet lat culture in vilro à $37^{\circ} \mathrm{C}$ du protiste parasite découvert dans le système génital des Primates. L'étude des diverses formes culturales amène à une première interprétation du cycle biologicue du parasite.

Mols-clés : Primales. Parasites génitaux. Milieu de culture.

The cultivation of a pathogenic Protist isolated from the genital system and some organs of Primates.

SUMMARY. A relatively simple diphasic medium, the composition of which is given, allow the cultivation in vilro at $37^{\circ} \mathrm{C}$ of the parasitic protist discovered in the genital system of Primates . From the study of the various cultural forms a first interpretation of the biological cycle of the parasite may be given.

Key-words: 1’rimates. Venereal parasites. Gulture medium.

Dans un précédent article (1), nous avons signalé l'existence d'un nouveau genre de Protistes parasites capables de provoquer d'importantes lésions des organes génitaux et de se propager ensuite à d'autres organes de Primates inférieurs, lémuriens et singes. Dans les divers cas que nous avons été amenés à étudier, nous nous sommes efforcés d'isoler à l'état pur et de cultiver ces Protistes.

A cet effet, nos premières tentatives ont consisté à ensemencer, d'une pari, des milieux classiques pour protozoaires (milieu à l'œuf, milieu au sérum coagulé, additionnés d'une phase liquide constituée de liquide de Ringer + albumine, ou de Ringer + sérum de cheval, dans laquelle sont en suspension de fines particules d'amidon de riz) et, d'autre part, les milieux bien connus destinés à l'isolement

* Laboratoire de Recherches el de Diagnosties de la Ménugerie, Chaire d'Élhologie el Conservation des Espèces animales, Muséum National d'Histoire Nalurelle, 57, rue Cuvier, F 75231 Paris Cedex 05.

Accepté le 6 décembre 1986 . 
des champignons microscopiques (milieu de Sabouraud solide ou liquide), additionnés ou non d'un antibiotique, chloramphénicol ou gentamycine.

Ainsi avons-nous pu d'abord constater que :

$a$ - dans la plupart des cas, l'apparition des formes myxamibiennes du protiste n'avait lieu qu'après plusieurs jours, voire plusieurs semaines ;

$b$ - dans les milieux pour protozoaires, la présence de très nombreux grains d'amidon et une prolifération bactérienne excessive rendaient difficile l'observation des formes évolutives du protiste;

$c-$ les milieux mycologiques additionnés d'antibiotiques étaient évidemment mo:ns faborables à la pullulation des bactéries, mais nous n'y obtenions que des cultures assez chétives du protiste.

A l'évidence, il fallait donc, d'une part, stimuler la multiplication de ce dernier en enrichissant le milieu, d'autre part, freiner celle des bactéries par un autre type d'antibiotique, et enfin éviter l'emploi d'amidon de riz. Après divers essais, nous avons pu atteindre ce triple objectif et mettre au point un milieu de culture diphasique dont la composition est la suivante :

Phase solide - C'est le milieu de Loeffler, commercialisé par l'Institut Pasteur.

Phase liquide - Nous l'obtenons en mélangeant $30 \mathrm{ml}$ de milieu liquide de Sabouraud, $10 \mathrm{ml}$ de sérum de cheval, filtré, stérile, $10 \mathrm{ml}$ d'extrait globulaire, $5 \mathrm{ml}$ de solution de Ringer, $5 \mathrm{ml}$ de solution saline tamponnée à $\mathrm{pH}$ 7. Cette dernière est obtenue en mélangeant : $19 \mathrm{ml}$ de solution aqueuse de phosphate monopotassique à $9,07 \%$ oo $31 \mathrm{ml}$ de solution aqueuse de phosphate disodique à $9,46 \%$; $450 \mathrm{ml}$ de solution aqueuse de chlorure de sodium à $8,5 \%$.

A ces $60 \mathrm{ml}$ de phase liquide, nous ajoutons $1 / 2 \mathrm{ml}$ d'une préparation destinée à l'enrichissement de milieux de culture pour germes exigeants (Poly-Vitex*), qui contient, en gramme par litre :

\begin{tabular}{|c|c|}
\hline Vitamine $\mathrm{B} 12$ & 0,010 \\
\hline L-glutamine . . & 10,000 \\
\hline Adénine ..... & 1,000 \\
\hline Chlorhydrate de Guanine ... & 0,030 \\
\hline Acide para-aminobenzoïque . & 0,013 \\
\hline tine & 1,100 \\
\hline 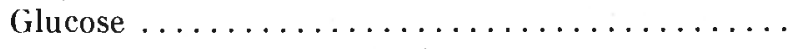 & 100,000 \\
\hline Diphosphopyridine nucléotide oxydé ......... & 0,250 \\
\hline 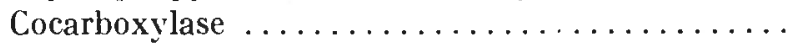 & 0,100 \\
\hline Nitrate ferrique .. & 0,020 \\
\hline Chlorhydrate de thiamine ... & 0,003 \\
\hline Chlorhydrate de cystéine .. & 25,900 \\
\hline
\end{tabular}

* BioMérieux, Marcy-l’Étoile, France. 
Nous y ajoutons aussi $2 \mathrm{ml}$ d'une préparation de gluconate de magnésium**, correspondant en magnésium métal à $0,2088 \mathrm{mg}$ et en glucose à $0,2 \mathrm{~g}$.

Ce milieu liquide, préparé dans des conditions d'asepsie rigoureuse, est en outre filtré sur membrane de $0,2 \mu$ de porosité, pendant sa répartition à raison de $2,5 \mathrm{ml}$ par tube de milieu de Loeffler.

Pour entraver le développement des bactéries, l'antibiotique qui nous a donné les meilleurs résultats est le sulfate de nétilmicine ("Nétromicine "Unilabo), à la dose de $50 \mathrm{mg}$ par tube. A la température de $+4^{\circ} \mathrm{C}$, le milieu conserve ses propriétés pendant plusieurs jours, et jusqu'à un mois.

Les tubes sont remis à la température du laboratoire avant d'être ensemencés. La culture est effectuée à l'étuve à $37^{\circ}$.

L'emploi de ce milieu nous a permis d'obtenir de bonnes cultures à partir des divers prélèvements suivants : utérus et liquide amniotique de microcèbe ; vésicules séminales de microcèbe ; placenta de gibbon et de cercocèbe ; rein et urine de microcèbe ; poumon de cercocèbe ; liquide pleural de microcèbe ; rate de cercocèbe et de microcèbe; exsudat péritonéal de microcèbe; foie de microcèbe. Ceci nous permet d'affirmer que le parasite est capable de s'implanter en divers tissus et organes en émigrant de l'appareil génito-urinaire.

Dans les divers cas énumérés ci-dessus, nous avons effectué de multiples examens microscopiques des cultures, à l'état frais, entre lame et lamelle, avec ou sans contraste de phase ou d'interférence, ou bien après coloration. Cette longue étude, poursuivie pendant plus de cinq ans, nous amène à classer de la façon suivante les divers aspects que revêt le parasite en culture.

A - Formes myxamibiennes :

a- isolées (fig. 1)

$b$ - groupées (fig. 2)

B -- Formes pseudoplasmodiales :

a - en formation (fig. 3)

$b$ - jeunes (fig. 4)

c - intermédiaires (fig. 5)

$d$-- achevées, fructifiantes (fig. 6)

C -- Formes kystiques :

a - dérivant de myxamibe isolée (fig. 7)

$b$--- produite à la surface du plasmode (fig. 8)

$c$ - correspondant à une partie de plasmode (fig. 9)

D - Pseudoplasmodes oophores :

Dans lesquels semble avoir lieu une conjugaison de noyaux, avec formation d'un ouf (fig. 10, 11, 12).

* Magnésium-Oligosol, Iabcatal, Montrouge, France. 

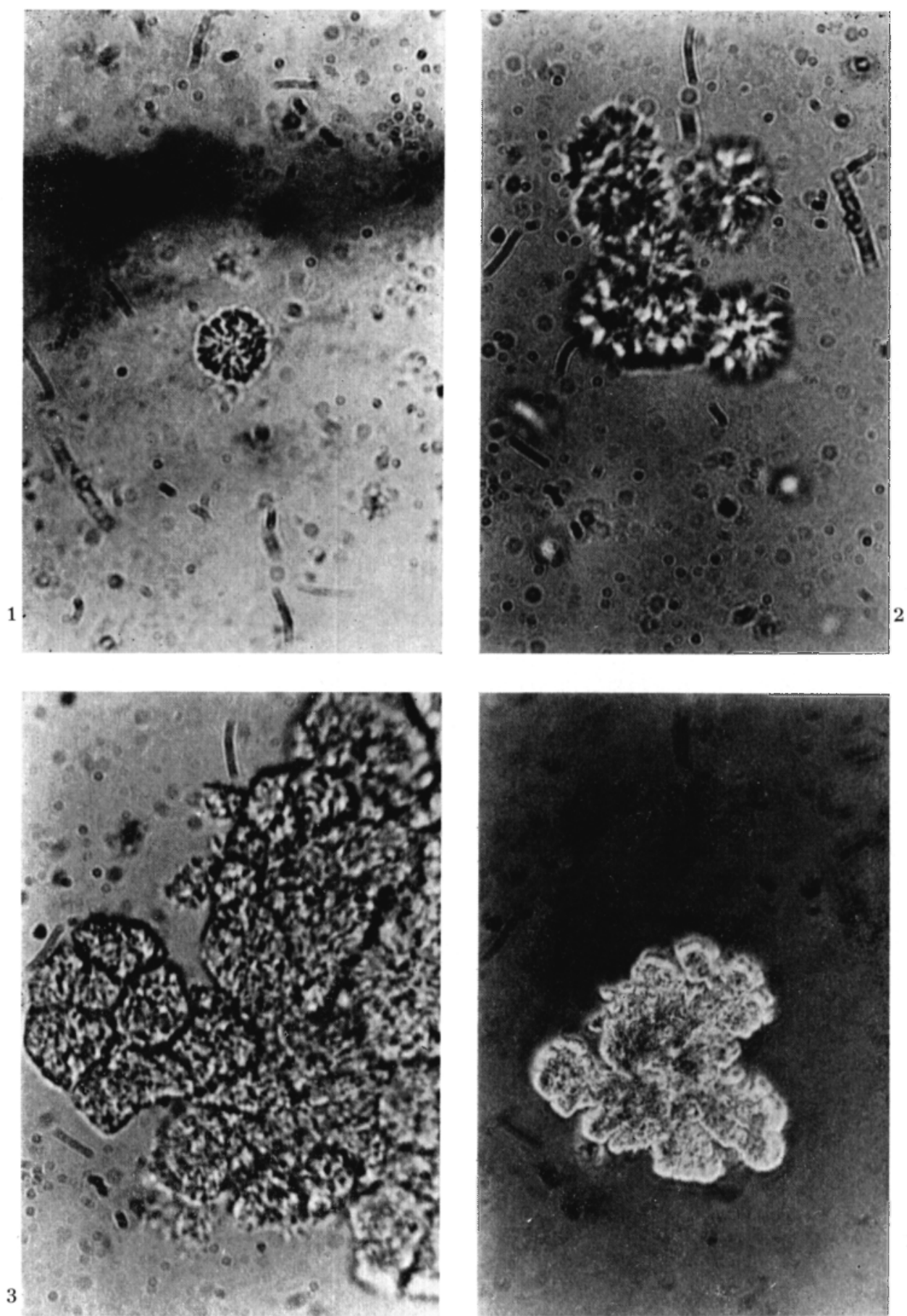

FIG. 1. - Forme myxamibe, dans une culture à parlir de poumon de cercocèbe. Obj. imm. $100 \times$.

FIG. 2. - Groupe de myxamibes, dans une autre culture de même origine. Obj. imm. $100 \times$ (Contraste de phase).

FIG. 3. - Myxamibes commençant à fusionner pour clommer un pseucloplasmode; culture à partir de placenta de gibbon. Obj. imm. $100 \times$ (Contraste d'interférence).

FIg. 4. - Pseudoplasmode jeune; culture d'origine placentaire (gibbon). Obj. $40 x$, avec contraste de phase. 

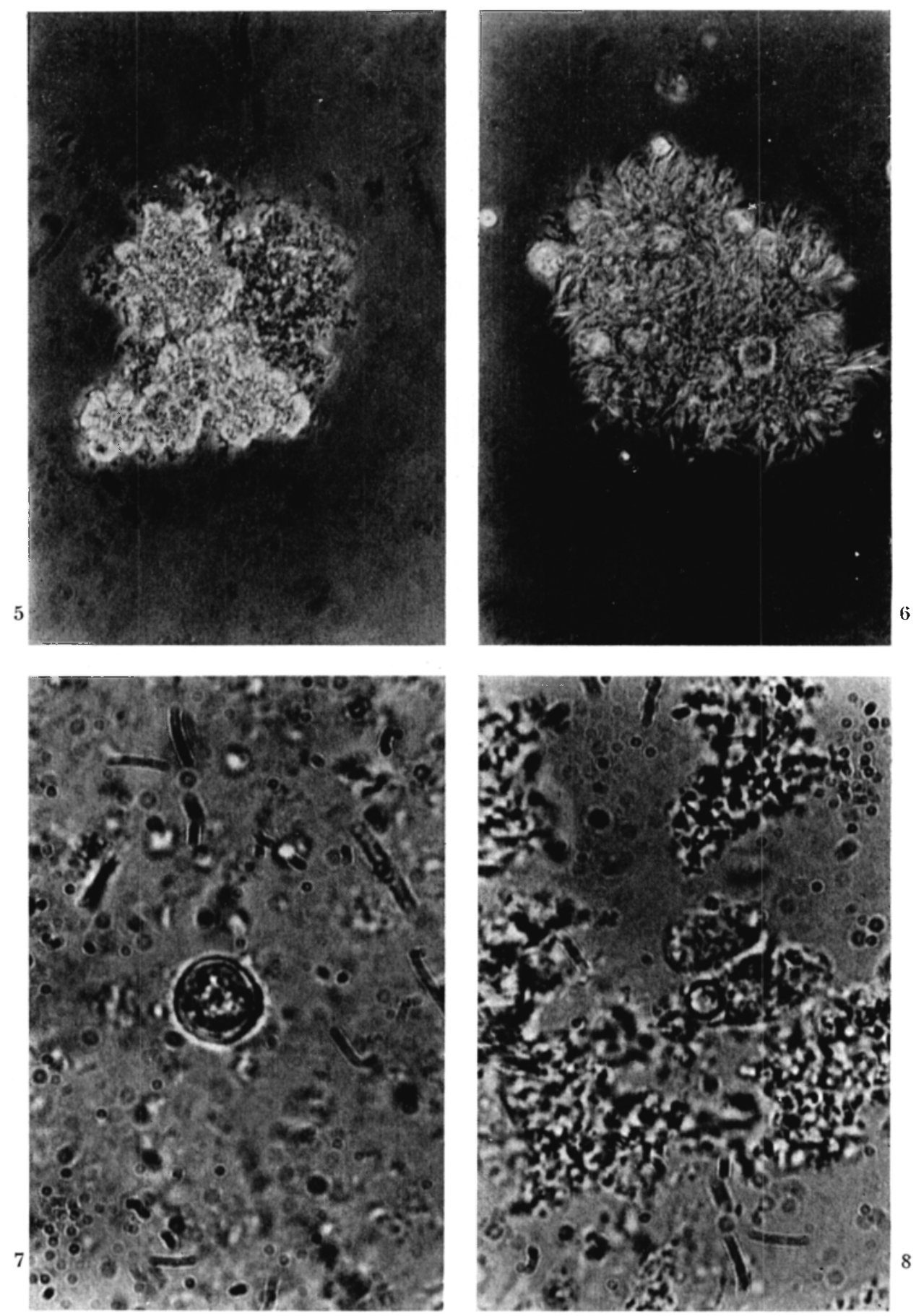

Fig. 5. - Forme pseudoplasmodiale plus évoluée; culture de mème origine. Obj. $40 \times$, avec contraste de phase.

FIG. 6. - Pseudoplasmode a mûr », formant des microkystes portés par de fines excroissances. Culture provenant du rein d'un microcèbe. Obj. $40^{\circ} \times$, contraste de phase.

FIG. 7. - Myxamibe enkystée ; culture à partir du poumon de cercocèbe. Obj. $100 \mathrm{x}$, avec contraste d'interférence.

FIr. 8. - Microkyste formé à la surface d'un plasmode ; culture à partir de l'utérus d'un microcèbe. Obj. imm. $100 \times$, contraste d'interférence. 

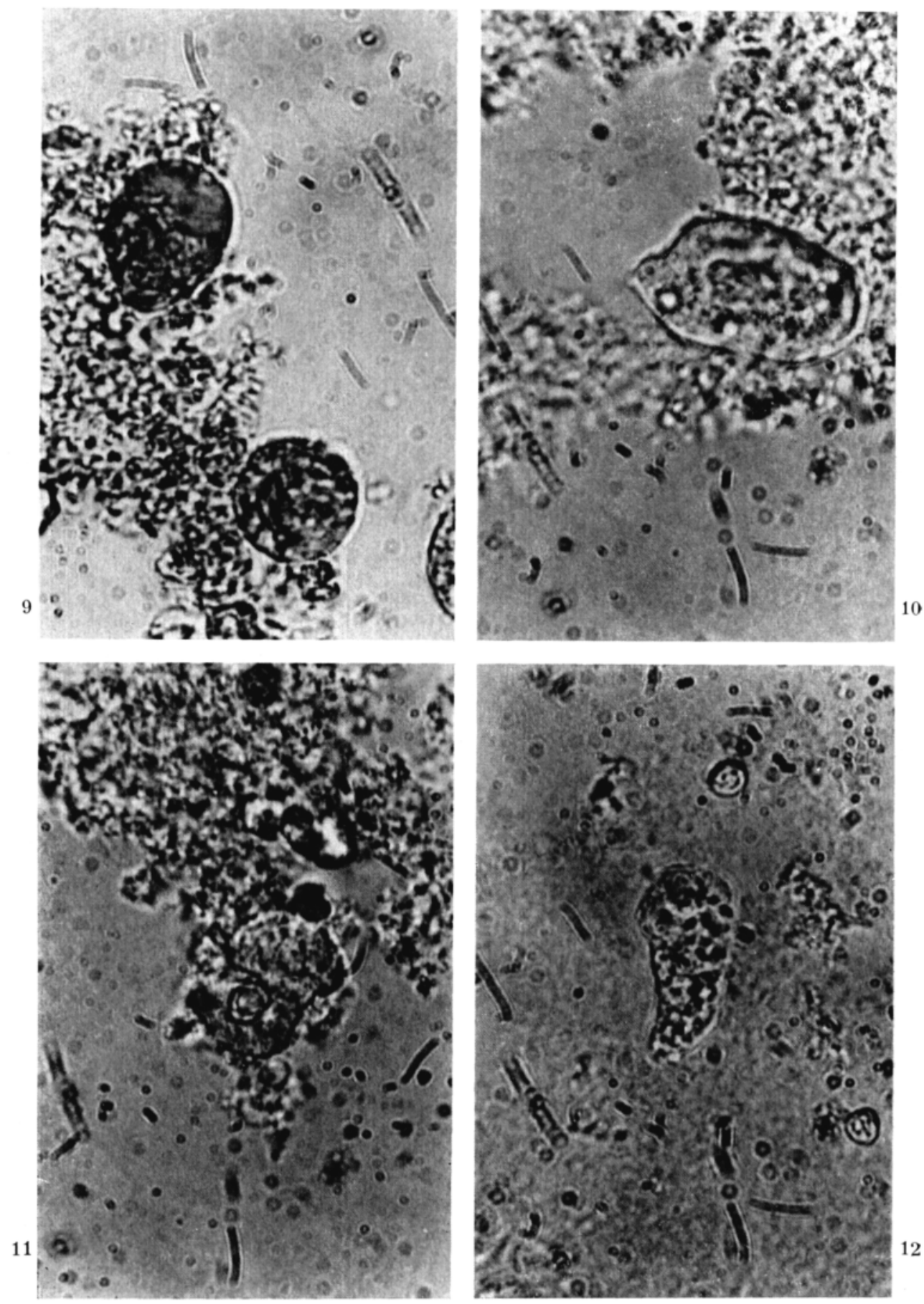

FIG. 9. - Kystes plus volumineux formés par isolement d'une fraction de plasmode ; culture à partir d'un pyomètre de microcèbe. Obj. $100 \times$, contraste interférentiel.

FIG. 10. - Pseudoplasmode oophore, avant la conjugaison de deux noyaux nettement visibles; culture provenant du poumon de cercocèbe. Obj. $100 \times$, contraste interférentiel.

FIg. 11. - Pseudoplasmode oophore dans lequel la fusion des noyaux a eu lieu ; l'œuf est nettement visible. Culture à partir de liquide pleural d'un microcèbe. Obj. imm. $100 \times$, contraste interférentiel.

FIg. 12. - Pseudoplasmode oophore et, à proximité, deux microkystes semblables à celui de la figure 8 ; culture provenant de l'utérus de microcèbe. Obj. imm., contraste interférentiel. 
Ces formes nous paraissent particulièrement intéressantes, car elles ressemblent aux plus grosses formes parasitaires que nous ayons décelées dans les coupes histologiques d'organes atteints (1).

Il semble donc que l'on soit en présence d'un cycle biologique à deux phases: l'une asexuée, assurant la dissémination de formes infestantes, qui sont en même temps des formes de résistance (kystes myxamibiens et kystes pseudoplasmodiaux), l'autre sexuée (pseudoplasmodes oophores), assurant la pérennité de l'espèce.

\section{BIBLIOGRAPHIE}

1. Chacvier G., Mortier-Gabet J. : Découverte d'un Protiste parasite apparenté aux Acrasiés dans l'appareil génital et les viscères de Primates. Ann. Parasilol, Hum. Comp., 1986, 61, 401-410. 